\title{
Analysis of Stress Characteristics and the Engineering Application of the Self-Balancing Retaining Wall
}

\author{
Fei Gan, ${ }^{1,2}$ XiaoMing Ye, ${ }^{1,2}$ Ke Yin, ${ }^{1,2}$ Meilin $\mathrm{Li}^{3}$ and Jing $\mathrm{Bi}^{1,2}$ \\ ${ }^{1}$ School of Civil Engineering, Chongqing University, Chongqing 400045, China \\ ${ }^{2}$ Key Laboratory of New Technology for Construction of Cities in Mountain Area, Chongqing University, Ministry of Education, \\ Chongqing 400045, China \\ ${ }^{3}$ Housing and Urban-Rural Development Bureau of Wudang, Guiyang 550018, China
}

Correspondence should be addressed to Jing Bi; demonjjun@yahoo.com

Received 12 May 2017; Accepted 3 August 2017; Published 11 September 2017

Academic Editor: Ying Li

Copyright (C) 2017 Fei Gan et al. This is an open access article distributed under the Creative Commons Attribution License, which permits unrestricted use, distribution, and reproduction in any medium, provided the original work is properly cited.

\begin{abstract}
A new type of retaining wall, the self-balance retaining wall, is introduced in this paper. Based on the stress analysis, the calculation model and method are advanced about the retaining wall. A comparative analysis related to traditional retaining wall is carried out on stress and cost combining with an actual project. The results show that the idea of using upper gravity retaining wall as the resistance of lower retaining wall is clever and reasonable that the self-balance retaining wall has a very wide scope of application relying on the anchor tensile conditions rarely and that the self-balance retaining wall has a great economic value with low cost. The cost of the self-balance retaining wall is $50 \%$ compared with the cantilever pile retaining wall under the same conditions which has a good economic effect and application prospect.
\end{abstract}

\section{Introduction}

China is an eastern country with frequent geological disasters. Since the 1980s, landslide, collapse, debris flow, and other geological disasters showed a trend of increase year by year with the rapid development of economic construction and the influence of natural factor [1]. Chongqing, which has typical mountain topography, is a famous mountain city in China. People in Chongqing often need to dig mountain or fill in ravine during the production and construction. This activity formed a large number of man-made slopes and greatly increases the construction cost. Since the construction of Three Gorges Dam, the cost used to govern geological disasters and slops occupies a large proportion in the whole city construction investment. Because of the different factors such as geological conditions and structures, construction cost and construction difficulty of retaining walls have a large difference. So, in order to save construction costs, reduce the construction difficulty, and improve construction efficiency, the supporting plan should be set up according to the specific geological terrain environment conditions reasonably.
A lot of scholars have done a lot of work about slopes (slide) in the aspect of theoretical research [2-6], while the supporting structure form of retaining wall has no obvious development. The forms of supporting structure of the retaining walls are single. Such as plate pile retaining wall, pull anchor pile retaining wall and door type pile retaining wall have their own conditions of use [7-23]. High fill retaining wall is one of the biggest problems in the slope engineering because of its high investment and big constructing difficulties. When the anchor is not considered, the disadvantages of retaining walls include high investment, high packing requirements, and demanding construction conditions restricting the rapid development of our country.

In order to develop the structure of retaining wall, Ye and Gan [24-27] did much research on retaining wall of balance, truss vertical anchor retaining wall, and folded plate pile retaining wall. In this paper, a new type of embankment retaining wall, self-balancing retaining wall, has been researched. The research makes up the shortage of the slope retaining wall in this arear $[28,29]$. 


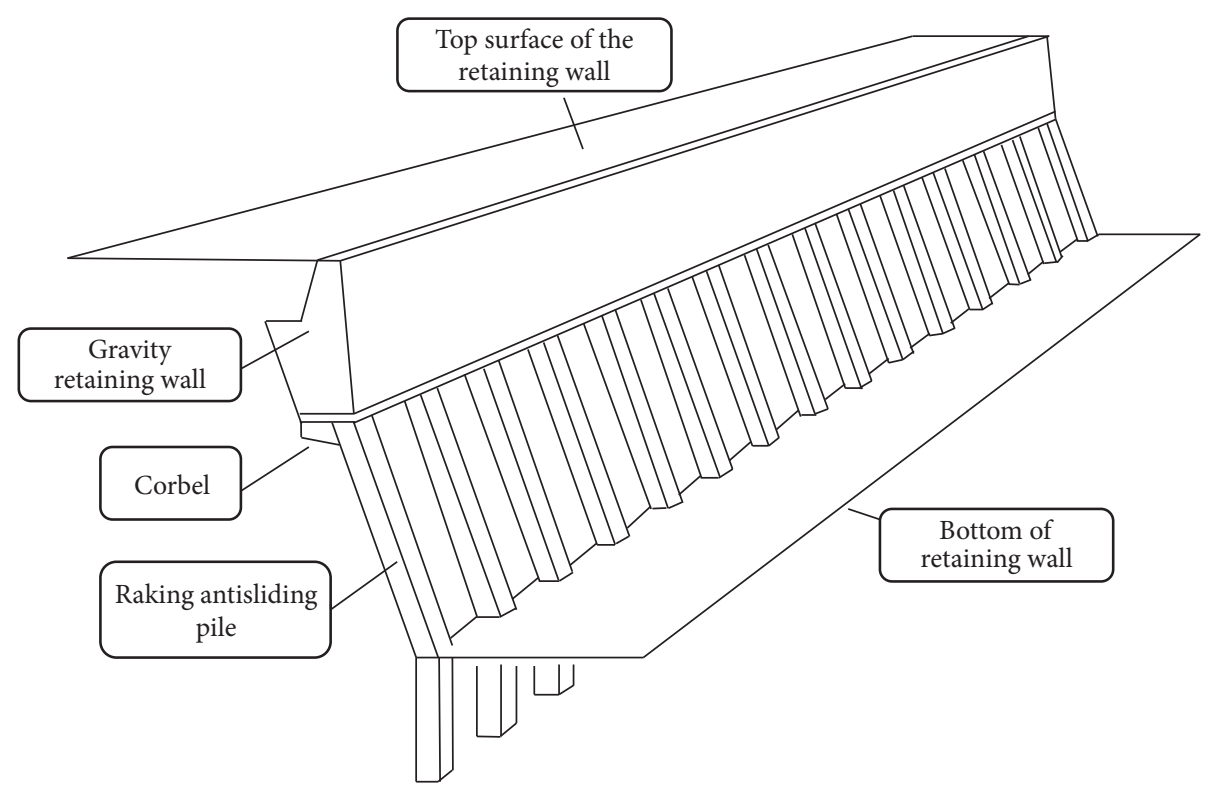

Figure 1: The overall schematic of the self-balancing retaining wall.

\section{Structure of Self-Balance Retaining Wall}

2.1. Configuration Introduction. The self-balance retaining wall is a new type slope supporting structure. The self-balance retaining wall is composed with gravity retaining wall in the upper part of the structure and antisliding pile in the lower part of the structure. This structure form makes full use of the inherent nature of gravity retaining wall. The instruction diagram is shown in Figures 1 and 2.

Gravity retaining wall is characterized by simple structure, large section size, heavier wall body, and simple construction technology. So, the gravity retaining wall is widely used in practical engineering. The gravity retaining walls use the earth pressure against its own gravity function. Its biggest advantage and intrinsic properties are gravity. The self-balance retaining wall is the first to use this resource to expand the gravity from its soil retaining effect to benefit the lower part of the retaining wall. The height of gravity retaining wall should be controlled in the range of $10 \mathrm{~m}$ considering the security and economy.

The characteristics of the antislide pile are antisliding ability, good effect of retaining, small disturbance on the stability of sliding body, construction safety, flexible pile position setting, timely supplement sliding resistance, and so on. The self-balance retaining wall makes full use of the advantages of antislide pile with some improvement on traditional antislide pile: firstly, the antislide pile is inclined pile. The angles of deviation of the antipile from the plumb line are about $10 \sim 20^{\circ}$. Furthermore, bracket is designed on the top of piles and the pile head coupling beam is set on the bracket. Then, the gravity retaining wall is set on the pile head coupling beam. Finally, in the embankment engineering, the antislide pile under the ground is the straight pile for the convenient installation, while the antislide pile is inclined piles in the process of excavation. The inclined piles, which

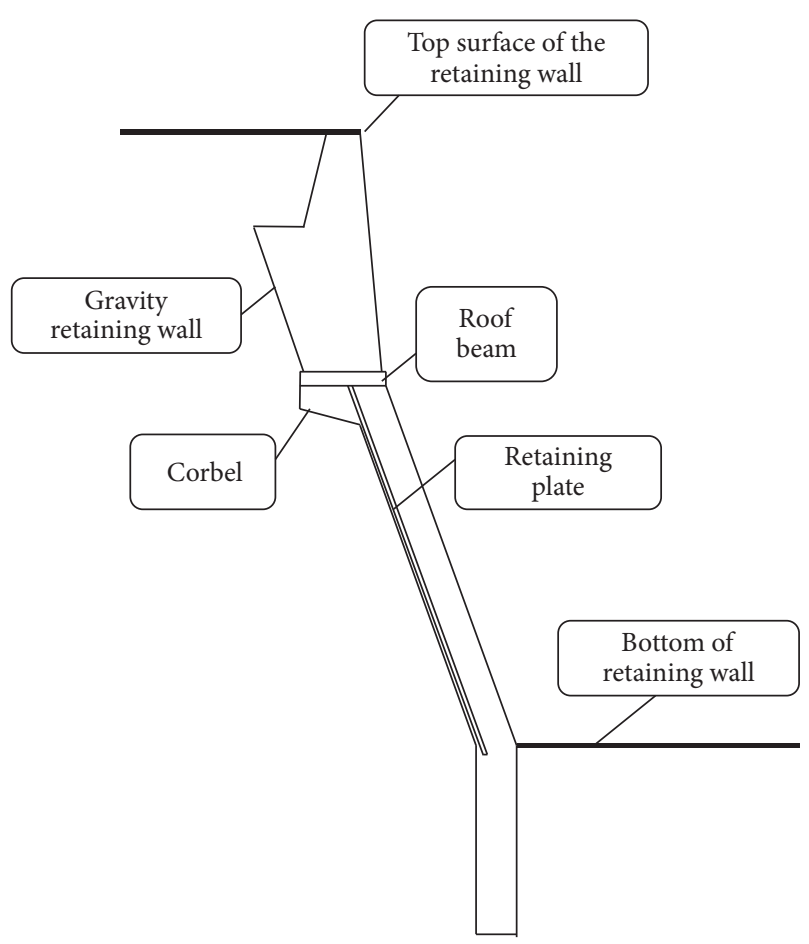

FIGURE 2: Sketch map of the balance of retaining wall.

are the secondary significant creation, greatly reduced the soil pressure.

2.2. Supporting Principle. The self-balance retaining wall is a new type of combined retaining wall. The self-balance retaining wall uses vertical load eccentricity of gravity retaining wall on the lower inclined pile to form a negative bending 


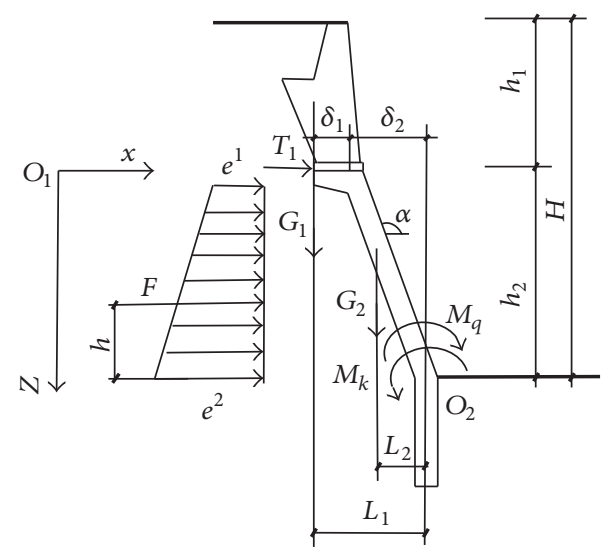

FIGURE 3: Sketch map of self-balancing retaining wall stress analysis.

moment and the angle of inclined piles against sliding of earth pressure to decrease supporting internal force of pile.

The stressed state analysis of the self-balance retaining wall is shown in Figure 3. There is an eccentric certain distance, $L_{1}$, between the gravity retaining wall and axis of piles embedded segment. $L_{1}$ is composed of two parts $\left(L_{1}=\delta_{1}+\delta_{2}\right)$ : the width of base size of gravity retaining wall is longer than the height of pile body $\delta_{1} ; \delta_{2}$ is the eccentric distance because the antislide raking pile produces eccentric distance. The distance between the center of mass of antisliding inclined pile and the axis of embedded antislide pile is $L_{2}$. Vertical load of gravity retaining wall is $G_{1}$. The gravity of antisliding pile is $G_{2}$. The resultant force of Coulomb's earth pressure is $F$, and the distance between the base of slope and force is $h$.

The bending moment produced by slope thrust at the base of slopes is

$$
M_{q}=F h
$$

The resistance bending moment at the bottom of pile core axis generated by the vertical load of gravity retaining wall and the gravity antisliding inclined pile is

$$
M_{k}=G_{1} L_{1}+G_{2} L_{2} .
$$

Adjust the unit weight of gravity retaining wall and antisliding inclined pile to make the resistance $M_{k}$ closing or equal to load $M_{q}$. The retaining wall can be called all balance retaining wall when $M_{k}=M_{q}$. When $M_{k}<M_{q}$, it is called part of the balance of retaining wall. This retaining wall needs part of flexural reinforced.

2.3. Computing Method. The computation of gravity retaining wall using traditional method is not stated here.

The soil pressure of antisliding inclined pile is calculated according to (5) in specification of slope:

$$
\begin{aligned}
e_{a} & =\gamma H K_{a} \\
E_{a} & =\frac{1}{2} \gamma H^{2} K_{a} \\
K_{a} & =\frac{\sin (\alpha+\beta)}{\sin ^{2} \alpha \sin ^{2}(\alpha+\beta-\varphi-\delta)}\left\{K_{q}[\sin (\alpha+\delta) \sin (\alpha-\delta)+\sin (\alpha+\beta) \sin (\alpha-\beta)]\right. \\
& +[2 \eta \sin \alpha \cos \varphi \cos (\alpha+\beta-\varphi-\delta)] \\
& \left.-2 \sqrt{K_{q} \sin (\alpha+\beta) \sin (\varphi-\beta)+\eta \sin \alpha \cos \varphi} \sqrt{K_{q} \sin (\alpha-\delta) \sin (\varphi+\delta)+\eta \sin \alpha \cos \varphi}\right\} \\
K_{q} & =1+\frac{2 q \sin \alpha \cos \beta}{\gamma H \sin (\alpha+\beta)} \\
\eta & =\frac{2 c}{\gamma H},
\end{aligned}
$$

where $e_{a}$ is earth pressure of arbitrary point $\left(\mathrm{kN} / \mathrm{m}^{2}\right) ; E_{a}$ is total force of soil pressure according to the load annotation $(\mathrm{kN} / \mathrm{m}) ; K_{a}$ is coefficient of active earth pressure; $H$ is the height of the retaining wall $(\mathrm{m}) ; \gamma$ is soil heavy $\left(\mathrm{kN} / \mathrm{m}^{3}\right) ; c$ is the cohesive force of soil $(\mathrm{kPa}) ; \varphi$ is the internal friction angle of soil $\left({ }^{\circ}\right) ; q$ is the standard values of surface uniformly distributed load $\left(\mathrm{kN} / \mathrm{m}^{2}\right) ; \delta$ is the friction angle of soil to the back of the retaining wall $\left(^{\circ}\right) ; \beta$ is the angles of deviation of the filled soil surface from the horizontal plane $\left({ }^{\circ}\right) ; \alpha$ is the angles of deviation of the retaining wall structure back from the horizontal plane $\left(^{\circ}\right)$.

One of the biggest contributions of this new type structure is that there is a dip angle in the antipile. Soil pressure decreases significantly. Take a set of data to calculate the following: slope height is $H=10 \mathrm{~m}$, soil heavy is $\gamma=$ $20 \mathrm{kN} / \mathrm{m}^{3}$, the comprehensive internal friction angle of filling soil $\varphi=30^{\circ}, \varphi=35^{\circ}, \varphi=40^{\circ}$, and overcharge on ground $q=30 \mathrm{kN} / \mathrm{m}^{2}$; calculate the soil pressure $E_{a}$ with different 


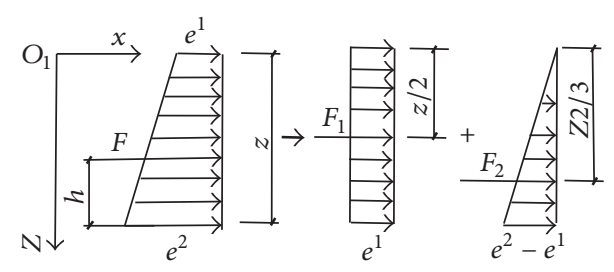

FIGURE 4: Sketch map of antisliding inclined pile soil stress analysis.

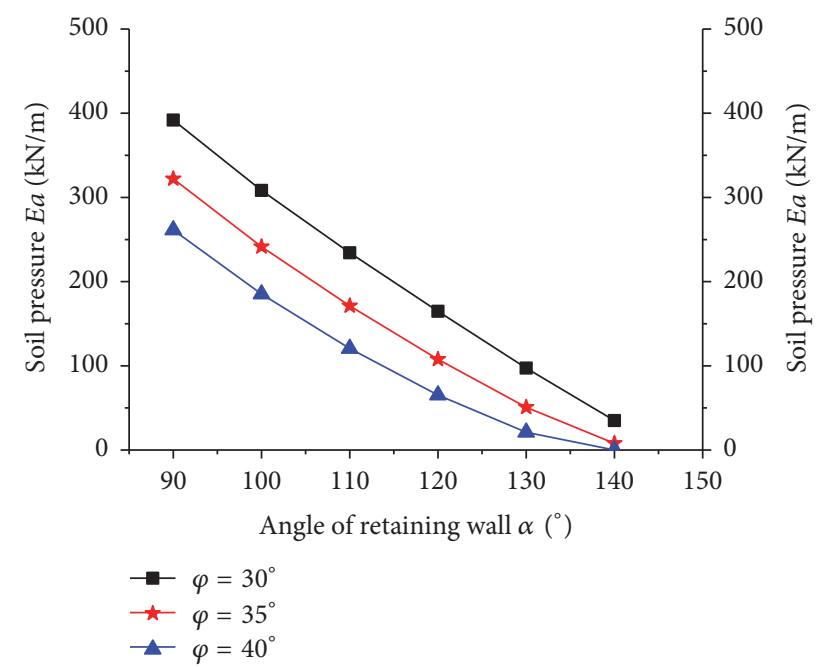

FIGURE 5: The curve of the soil pressure changing with angle.

dip angles of retaining wall $\alpha=90^{\circ}, \alpha=100^{\circ}, \alpha=110^{\circ}$, $\alpha=120^{\circ}, \alpha=130^{\circ}$, and $\alpha=140^{\circ}$ as shown in Figure 4 . As shown in Figure 5, the earth pressure on retaining wall is decreasing nonlinear with the increasing of retaining dip angle. The earth pressure decreases faster when the internal friction angle of soil is lower. When the internal friction angle of soil is $\varphi=30^{\circ}$ and $\alpha=90^{\circ}$, the earth pressure is $391.84 \mathrm{kN} / \mathrm{m}$; if $\alpha=110^{\circ}$, the earth pressure is $234.23 \mathrm{kN} / \mathrm{m}$. When the angle increases $20^{\circ}$, the earth pressure decreases $40.22 \%$. That is to say, changing the antisliding inclined pile inclination has obvious effect to reduce the earth pressure.

The internal force calculation of pile body of antisliding inclined pile upper than the embedded surface is assumed that the embedded part is fixed bearing, the inclined pile is assumed as statically determinate structure, and analysis of stress state is shown in Figures 3 and 4.

Soil pressure load bending moment is $M_{1}$, and soil pressure in the raking pile segment is distributed as trapezoid. The soil pressure is simplified into a rectangular distribution and triangular distribution.

$$
\begin{aligned}
M_{1} & =s\left[\frac{1}{2} e_{1} z^{2}+\frac{1}{3} e_{1} z^{2}\left(e_{2}-e_{1}\right)\right] \\
& =s z^{2}\left[\frac{1}{6} e_{1}+\frac{1}{3} e_{2}\right] .
\end{aligned}
$$

The horizontal force of upper gravity retaining wall basement is $T$, and the bending moment is $M_{2}$

$$
M_{2}=s T z .
$$

The vertical load of upper gravity retaining wall basement is $G_{1}$, and the bending moment is $M_{3}$

$$
M_{3}=s G_{1}(\delta-z \cot \alpha) .
$$

The weight load of antisliding raking pile is $G_{2}$, and the bending moment is $M_{4}$

$$
M_{4}=\frac{b h z^{2} \gamma}{2 \sin \alpha} .
$$

The internal force moment at $z$ point of antisliding raking pile is $M_{z}$

$$
\begin{aligned}
& M_{z}=M_{1}+M_{2}-M_{3}-M_{4} \\
& s\left[\left(\frac{1}{6} e_{1}+\frac{1}{3} e_{2}\right) z^{2}+T Z-G_{1}(\delta-z \cot \alpha)\right] \\
& \quad-\frac{1}{6} b h z^{2} \gamma
\end{aligned}
$$

The shear stress at point $z$ of antisliding raking pile is $V_{z}$

$$
V_{z}=s\left[T+\frac{1}{2} z\left(e_{1}+e_{2}\right)\right]-\frac{1}{6} b h z^{2},
$$

where $e_{1}$ is earth pressure of corbel on the top of antislide pile $\left(\mathrm{kN} / \mathrm{m}^{2}\right) ; e_{2}$ is earth pressure of the embedded surface of antislide pile $\left(\mathrm{kN} / \mathrm{m}^{2}\right) ; z$ is the distance between the top of antislide pile and the section of pile (m); $s$ is the horizontal distance between antislide piles (m); $G_{1}$ is vertical load of vertical load $(\mathrm{kN} / \mathrm{m}) ; G_{2}$ is weight of antislide pile $(\mathrm{kN}) ; \delta$ is eccentric distance between vertical load of gravity retaining wall and inclined pile center $(\mathrm{m}) ; \alpha$ is the angles of deviation of the retaining wall structure back from the horizontal plane $\left({ }^{\circ}\right) ; b$ is the width of the retaining wall $(\mathrm{m}) ; h$ is the height of the retaining wall $(\mathrm{m}) ; \gamma$ is unit weight of reinforced concrete $\left(\mathrm{kN} / \mathrm{m}^{3}\right)$.

The deformation coefficient of pile is firstly introduced when the internal force, displacement, and lateral compressive stress of embedded pile are calculated.

According to the " $K$ " method of calculation,

$$
\beta=\left(\frac{K B_{p}}{4 E I}\right)^{1 / 4} .
$$

According to the " $m$ " method of calculation,

$$
\alpha=\left(\frac{m B_{p}}{E I}\right)^{1 / 5},
$$

where $\alpha, \beta$ are deformation coefficient of the pile $\left(\mathrm{m}^{-1}\right) ; K$ is coefficient of foundation $\left(\mathrm{KN} / \mathrm{m}^{-3}\right) ; M$ is the proportion coefficient of coefficient of foundation changing with foundation depth $\left(\mathrm{kN} / \mathrm{m}^{-4}\right) ; E$ is elastic modulus of reinforced concrete of pile $(\mathrm{kPa}) ; I$ is the section moment of inertia of pile $\left(\mathrm{m}^{-4}\right) ; B_{p}$ : is calculating width of pile $(\mathrm{m})$. 
2.3.1. General Method of " $K$ ". The flexural differential equation of method of " $K$ " of elastic antislide pile is

$$
E I \frac{d^{4} y}{d z^{4}}=-K B_{P} y,
$$

where $y K B_{P}$ is the horizontal resist forces of foundation acting on pile $(\mathrm{kN} / \mathrm{m})$.

Introducing the deformation coefficient

$$
\beta=\left(\frac{K B_{p}}{4 E I}\right)^{1 / 4}
$$

(16) is changed to

$$
\frac{d^{4} y}{4 d z^{4}}+4 \beta^{4} y
$$

The displacement and internal force of any section under the sliding plan is

$$
\begin{aligned}
y_{z} & =y_{0} \varphi_{1}+\frac{\varphi_{0}}{\beta} \varphi_{2}+\frac{M_{0}}{\beta^{2} E I} \varphi_{3}+\frac{Q_{0}}{\beta^{3} E I} \varphi_{4} \\
\varphi_{z} & =\beta\left(-4 y_{0} \varphi_{4}+\frac{\varphi_{0}}{\beta} \varphi_{1}+\frac{M_{0}}{\beta^{2} E I} \varphi_{2}+\frac{Q_{0}}{\beta^{3} E I} \varphi_{3}\right) \\
\frac{M_{Z}}{\beta^{2} E I} & =-4 y_{0} \varphi_{3}+4 \frac{\varphi_{0}}{\beta} \varphi_{4}+\frac{M_{0}}{\beta^{2} E I} \varphi_{1}+\frac{Q_{0}}{\beta^{3} E I} \varphi_{2} \\
\frac{Q_{Z}}{\beta^{3} E I} & =-4 x_{0} \varphi_{2}+4 \frac{\varphi_{0}}{\beta} \varphi_{3}-4 \frac{M_{0}}{\beta^{2} E I} \varphi_{4}+\frac{Q_{0}}{\beta^{3} E I} \varphi_{1},
\end{aligned}
$$

where $\varphi_{1}, \varphi_{2}, \varphi_{3}, \varphi_{4}$ is the influencing function of method " $K$,"

$$
\begin{aligned}
& \varphi_{1}=\cos \beta z \operatorname{ch} \beta z \\
& \varphi_{2}=\frac{1}{2}(\sin \beta z \operatorname{ch} \beta z+\cos \beta z \operatorname{sh} \beta z) \\
& \varphi_{3}=\frac{1}{2} \sin \beta z \operatorname{sh} \beta z \\
& \varphi_{4}=\frac{1}{2}(\sin \beta z \operatorname{ch} \beta z-\cos \beta z \operatorname{sh} \beta z) .
\end{aligned}
$$

Equation (19) is normal method of " $K$ " and $y_{0}$ and $\varphi_{0}$ on the surface of sliding should be calculated first. Then, the displacement and the internal force of any section in pile can be calculated. So, three boundary conditions should be confirmed:

(1) When the pile bottom is fixed, $y_{B}=0$ and $\varphi_{B}=$ 0 . Solving the simultaneous equations (19), (21), and (22),

$$
\begin{aligned}
& y_{o}=\frac{M_{O}}{\beta^{2} E I} \frac{\varphi_{2}{ }^{2}-M \varphi_{1} \varphi_{3}}{4 \varphi_{2} \varphi_{4}+\varphi_{1}{ }^{2}}+\frac{Q_{O}}{\beta^{3} E I} \frac{\varphi_{2} \varphi_{3}-\varphi_{1} \varphi_{4}}{4 \varphi_{2} \varphi_{4}+\varphi_{1}{ }^{2}} \\
& \theta_{o}=-\frac{M_{O}}{\beta E I} \frac{\varphi_{2} \varphi_{1}+4 \varphi_{4} \varphi_{3}}{4 \varphi_{2} \varphi_{4}+\varphi_{1}{ }^{2}}-\frac{Q_{O}}{\beta^{2} E I} \frac{\varphi_{1} \varphi_{3}+4 \varphi_{1}{ }^{2}}{4 \varphi_{2} \varphi_{4}+\varphi_{1}{ }^{2}}
\end{aligned}
$$

(2) When the pile bottom is hinged, $y_{B}=0$ and $M_{B}=$ 0 . Solving the simultaneous equations (19), (21), and (22),

$$
\begin{aligned}
& y_{o}=\frac{M_{O}}{\beta^{2} E I} \frac{4 \varphi_{3} \varphi_{4}+\varphi_{1} \varphi_{2}}{4 \varphi_{2} \varphi_{3}-4 \varphi_{1} \varphi_{4}}+\frac{Q_{O}}{\beta^{3} E I} \frac{4 \varphi_{4}{ }^{2}+\varphi_{2}{ }^{2}}{4 \varphi_{2} \varphi_{3}-4 \varphi_{1} \varphi_{4}} \\
& \theta_{o}=-\frac{M_{O}}{\beta E I} \frac{4 \varphi_{3}{ }^{2}+\varphi_{1}{ }^{2}}{4 \varphi_{2} \varphi_{3}-4 \varphi_{1} \varphi_{4}}-\frac{Q_{O}}{\beta^{2} E I} \frac{4 \varphi_{3} \varphi_{4}+\varphi_{1} \varphi_{2}}{4 \varphi_{2} \varphi_{3}-4 \varphi_{1} \varphi_{4}} .
\end{aligned}
$$

(3) When the pile bottom is free, $M_{B}=0$ and $Q_{B}=$ 0 . Solving the simultaneous equations (19), (21), and (22),

$$
\begin{aligned}
& y_{o}=\frac{M_{O}}{\beta^{2} E I} \frac{4 \varphi_{4}{ }^{2}+\varphi_{1} \varphi_{3}}{4 \varphi_{3}{ }^{2}-4 \varphi_{2} \varphi_{4}}+\frac{Q_{O}}{\beta^{3} E I} \frac{\varphi_{2} \varphi_{3}-\varphi_{1} \varphi_{4}}{4 \varphi_{3}{ }^{2}-4 \varphi_{2} \varphi_{4}} \\
& \theta_{o}=-\frac{M_{O}}{\beta E I} \frac{4 \varphi_{3} \varphi_{4}+\varphi_{1} \varphi_{2}}{4 \varphi_{3}{ }^{2}-4 \varphi_{2} \varphi_{4}}-\frac{Q_{O}}{\beta^{2} E I} \frac{\varphi_{2}{ }^{2}-\varphi_{1} \varphi_{3}}{4 \varphi_{3}{ }^{2}-4 \varphi_{2} \varphi_{4}} .
\end{aligned}
$$

The lateral stress of pile is

$$
\sigma=K y_{z}
$$

2.3.2. General Method of " $m$ ". The flexural differential equation of method of " $m$ " of elastic antislide pile is

$$
E I \frac{d^{4} y}{d z^{4}}=-B p y m x^{1 / n}
$$

Introducing the deformation coefficient $\alpha=\left(m B_{p}\right)$ $E I)^{1 /(4+1 / n)},(25)$ is changed to

$$
\frac{d^{4} y}{d z^{4}}+\alpha^{4+1 / n} z^{1 / n} y=0
$$

The displacement and internal force of any section under the sliding plan is

$$
\begin{aligned}
y_{z} & =y_{0} A_{1}+\frac{\varphi_{0}}{\alpha} B_{1}+\frac{M_{0}}{\alpha^{2} E I} C_{1}+\frac{Q_{0}}{\alpha^{3} E I} D_{1} \\
\varphi_{z} & =\alpha\left(y_{0} A_{2}+\frac{\varphi_{0}}{\alpha} B_{2}+\frac{M_{0}}{\alpha^{2} E I} C_{2}+\frac{Q_{0}}{\alpha^{3} E I} D_{2}\right) \\
\frac{M_{Z}}{\alpha^{2} E I} & =y_{0} A_{3}+\frac{\varphi_{0}}{\alpha} B_{3}+\frac{M_{0}}{\alpha^{2} E I} C_{3}+\frac{Q_{0}}{\alpha^{3} E I} D_{3} \\
\frac{Q_{Z}}{\alpha^{3} E I} & =y_{0} A_{4}+\frac{\varphi_{0}}{\alpha} B_{4}+\frac{M_{0}}{\alpha^{2} E I} C_{4}+\frac{Q_{0}}{\alpha^{3} E I} D_{4},
\end{aligned}
$$

where $A_{i}, B_{i}, C_{i}$, and $D_{i}$, which are changing with conversional depth $\alpha x$, are the influencing function of method " $m$."

Equation (27) is normal method of " $m$ " and $y_{0}$ and $\varphi_{o}$ on the surface of sliding should be calculated first. Then, the displacement and the internal force of any section in pile can be calculated. So, three boundary conditions should be confirmed: 
TABLE 1: The design parameter.

\begin{tabular}{lcccc}
\hline Rock property & $\begin{array}{c}\text { Natural density } \\
\mathrm{kN} / \mathrm{m}^{3}\end{array}$ & $\begin{array}{c}\text { Saturated unit } \\
\text { weight } \\
\mathrm{kN} / \mathrm{m}^{3}\end{array}$ & $\begin{array}{c}\text { Cohesive force } \\
\mathrm{c} / \mathrm{kpa}\end{array}$ & $\begin{array}{c}\text { Internal friction } \\
\text { angle } \\
\varphi /^{\circ}\end{array}$ \\
\hline Filled soil & 18 & 20 & 0 & 28 \\
Highly weathered rock & 23.5 & 24.5 & & $\begin{array}{c}\text { Resistance } \\
\mathrm{k} / \mathrm{MN} / \mathrm{m}^{3}\end{array}$ \\
The middle weathered rock & 26.7 & 23.8 & 2490 & 33.6 \\
\hline
\end{tabular}

(1) When the pile bottom is fixed, $y_{B}=0$ and $\varphi_{B}=$ 0 . Solving the simultaneous equations (27), (21), and (22),

$y_{A}=\frac{M_{A}}{\alpha^{2} E I} \frac{B_{1} C_{2}-C_{1} B_{2}}{A_{1} B_{2}-B_{1} A_{2}}+\frac{Q_{A}}{\alpha^{3} E I} \frac{B_{1} D_{2}-D_{1} B_{2}}{A_{1} B_{2}-B_{1} A_{2}}$

$\varphi_{A}=\frac{M_{A}}{\alpha E I} \frac{C_{1} A_{2}-A_{1} C_{2}}{A_{1} B_{2}-B_{1} A_{2}}+\frac{Q_{A}}{\alpha^{2} E I} \frac{D_{1} A_{2}-A_{1} D_{2}}{A_{1} B_{2}-B_{1} A_{2}}$.

(2) When the pile bottom is hinged, $y_{B}=0$ and $M_{B}=$ 0 . Solving the simultaneous equations (27), (21), and (22),

$$
\begin{aligned}
& y_{A}=\frac{M_{A}}{\alpha^{2} E I} \frac{B_{3} C_{1}-C_{3} B_{1}}{A_{3} B_{1}-B_{3} A_{1}}+\frac{Q_{A}}{\alpha^{3} E I} \frac{B_{3} D_{1}-D_{3} B_{1}}{A_{1} B_{3}-B_{1} A_{3}} \\
& \varphi_{A}=\frac{M_{A}}{\alpha E I} \frac{C_{3} A_{1}-A_{3} C_{1}}{A_{3} B_{1}-B_{3} A_{1}}+\frac{Q_{A}}{\alpha^{2} E I} \frac{D_{3} A_{1}-A_{3} D_{1}}{A_{3} B_{1}-B_{3} A_{1}} .
\end{aligned}
$$

(3) When the pile bottom is free, $M_{B}=0$ and $Q_{B}=$ 0 . Solving the simultaneous equations (19), (21), and (22),

$$
\begin{aligned}
& y_{A}=\frac{M_{A}}{\alpha^{2} E I} \frac{B_{3} C_{4}-C_{3} B_{4}}{A_{3} B_{4}-B_{3} A_{4}}+\frac{Q_{A}}{\alpha^{3} E I} \frac{B_{3} D_{4}-D_{3} B_{4}}{A_{3} B_{4}-B_{3} A_{4}} \\
& \varphi_{A}=\frac{M_{A}}{\alpha E I} \frac{C_{3} A_{4}-A_{3} C_{4}}{A_{3} B_{4}-B_{3} A_{4}}+\frac{Q_{A}}{\alpha^{2} E I} \frac{D_{3} A_{4}-A_{3} D_{4}}{A_{3} B_{4}-B_{3} A_{4}} .
\end{aligned}
$$

The lateral stress of pile is

$$
\sigma=m z y_{z}
$$

\section{The Characteristics of Self-Balance Retaining Wall and Its Application Condition}

The characteristics of self-balance retaining wall are as follows:

(1) Antisliding pile is fastigiated, and the soil pressure is decreased. When the antisliding pile inclines $20^{\circ}$, Coulomb's earth pressure will decrease $40 \%$.

(2) The gravity of the upper gravity retaining wall is well used. The primary attributes of gravity retaining wall are the gravity. The self-balance retaining wall first utilizes this resource which expands the soil retaining effect from itself to the lower retaining wall with energy conservation and emissions reduction.
(3) The antislide pile bending moment is significantly reduced due to the reduction of soil thrust and force of self-balance.

(4) Reduce embedded requirements of the antislide pile.

(5) Balance problem in construction process. In the fill projects, the balance of self-balance retaining wall is very important. It is different from the other retaining wall and needs balance calculation.

(6) The range of application is as follows: (1) the filling slope controlled by Coulomb's earth pressure and (2) the slope with smooth surface of bedrock and without the condition of anchoring; the filling soil slope or half filling soil slope with height of 15-30 m.

\section{Analysis of Engineering Example}

An engineering example is used to illustrate the advantages of self-balance retaining wall to the traditional pile plate retaining wall.

4.1. Project Profile. The project is located in Chongqing Jiangbei harbour city industrial park zone D "light industrial park D area." There is a slope with length of $350 \mathrm{~m}$ and height of $20 \mathrm{~m}$ in the place. Slope position is the original deposit soil. The soil thickness is $15-35 \mathrm{~m}$. The lower bedrock is composed of mudstone and sandstone. The surface of the bedrock is smooth under the slope bottom elevation about 2-10 $\mathrm{m}$. The slope does not have the condition of anchoring. Authors illustrate the application of self-balance retaining wall in the comparison between two schemes. Calculation parameter is given in Table 1.

4.2. Design Parameter. Calculation parameter is given in Table 1 according to geological exploration report.

\subsection{Designing Scheme}

(1) Design 1: The Self-Balance Retaining Wall. The supporting earth pressure is controlled by Coulomb's earth pressure. The calculation section pile cross is $1.5 \mathrm{~m} \times 2.5 \mathrm{~m}$, distance between piles is $4 \mathrm{~m}$, rock-socketed depth is $6 \mathrm{~m}$, the height of gravity retaining wall is $9 \mathrm{~m}$, and dip angle of antisliding raking pile is $110^{\circ}$. The diagrammatic cross-section of selfbalance retaining wall is shown in Figure 6.

(2) Design 2: Cantilever Pile Retaining Wall. The calculation section pile cross is $2.5 \mathrm{~m} \times 4 \mathrm{~m}$, distance between piles is $4 \mathrm{~m}$, 


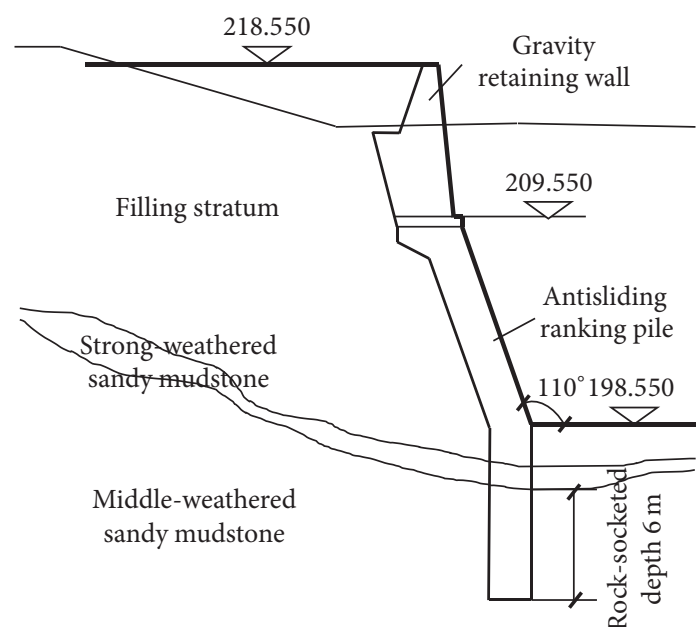

FIGURE 6: The diagram of the balance of retaining wall.

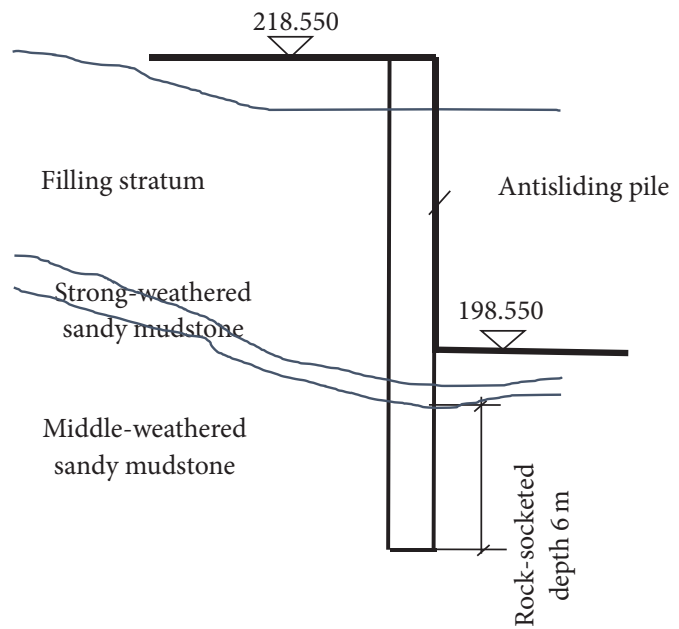

FIGURE 7: The diagram of retaining wall.

and rock-socketed depth is $10 \mathrm{~m}$. The diagrammatic crosssection of cantilever pile retaining wall is shown in Figure 7.

4.4. Force Analysis. The force of upper gravity retaining wall of self-balance retaining wall is calculated by the traditional method with Leading software 6.0. The soil pressure is calculated according to (3)-(7). Internal force of cantilever pile body is calculated according to (12) and (13). The embedded segment of pile is calculated by " $K$ " method according to (19), (20), and (22). The soil pressure in the front of the pile is calculated according to (24) and the frictional effect between soil and surface of wall is not considered. Because the calculation formula of internal force of self-balance retaining wall is more complex and there is no software to calculate it, authors use Matlab to calculate the internal force by programming. The comparison diagram of two kinds of support in the internal force is plotted in Figures 8 and 9. Reinforcement area of contrast is plotted in Figures 10 and 11. As shown in Figure 12, the pressure in the front of pile is listed in Figure 12.

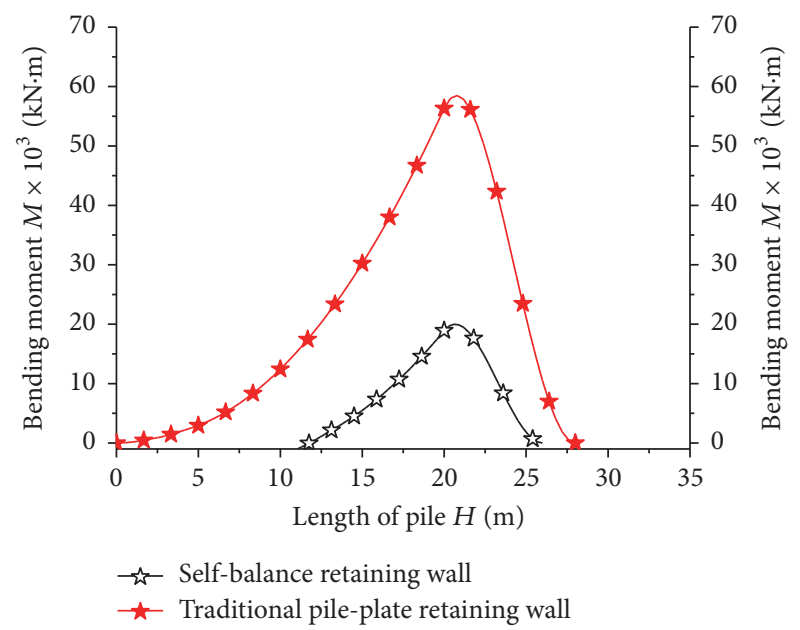

FIgURE 8: The pile bending moment diagram.

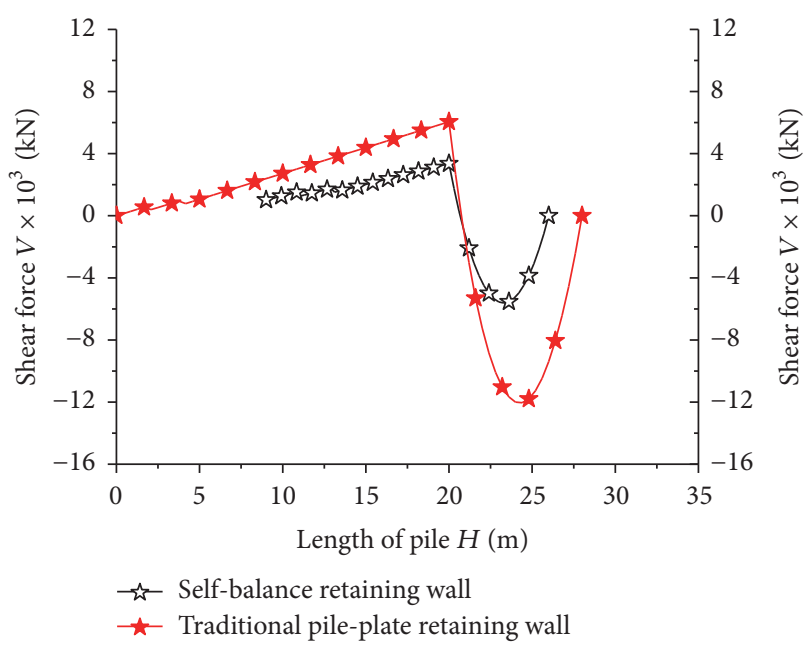

FIGURE 9: Antislide pile shear diagram.

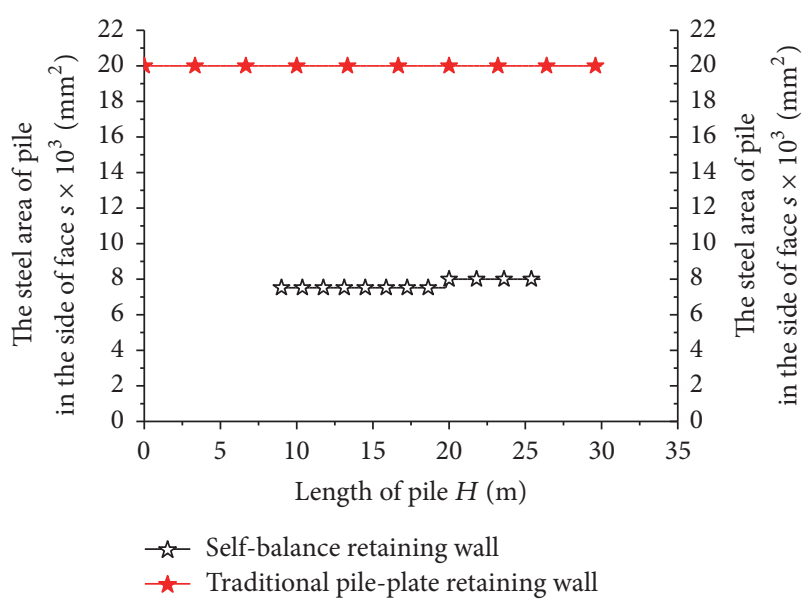

FIgURE 10: Antislide pile reinforcement area. 
TABLE 2: Comparison of the peak internal force.

\begin{tabular}{lccc}
\hline Contrastive analysis & $\begin{array}{c}\text { The maximum bending } \\
\text { moment } M / \mathrm{kN} \cdot \mathrm{m}\end{array}$ & $\begin{array}{c}\text { The maximum shear force } \\
V / \mathrm{Kn}\end{array}$ & $\begin{array}{c}\text { The biggest pile reaction } \\
P / \mathrm{kpa}\end{array}$ \\
\hline Traditional pile retaining wall & 53471.32 & 6144.38 & 3455.30 \\
Self-balance retaining wall & 15764.54 & 3678.98 & 2365.12 \\
Percent & $29.48 \%$ & $59.87 \%$ & $68.45 \%$ \\
\hline
\end{tabular}

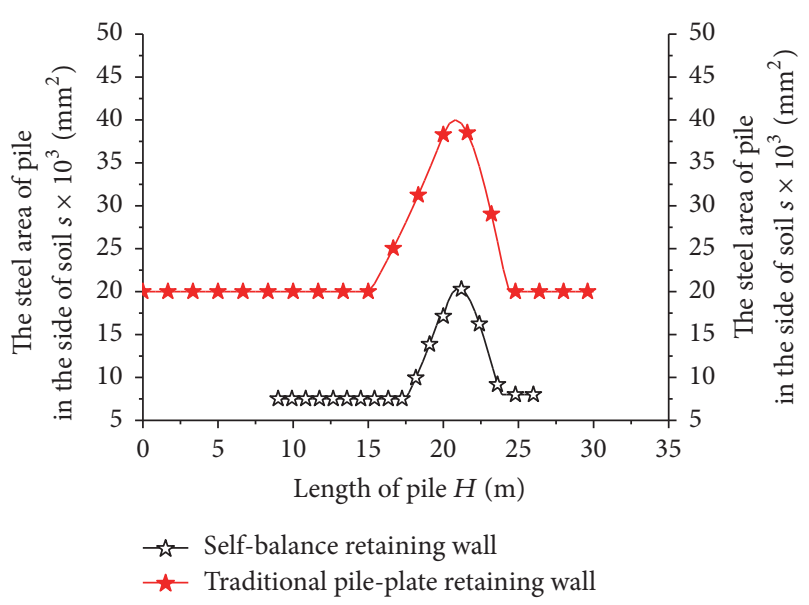

FIGURE 11: Antislide pile reinforcement area.

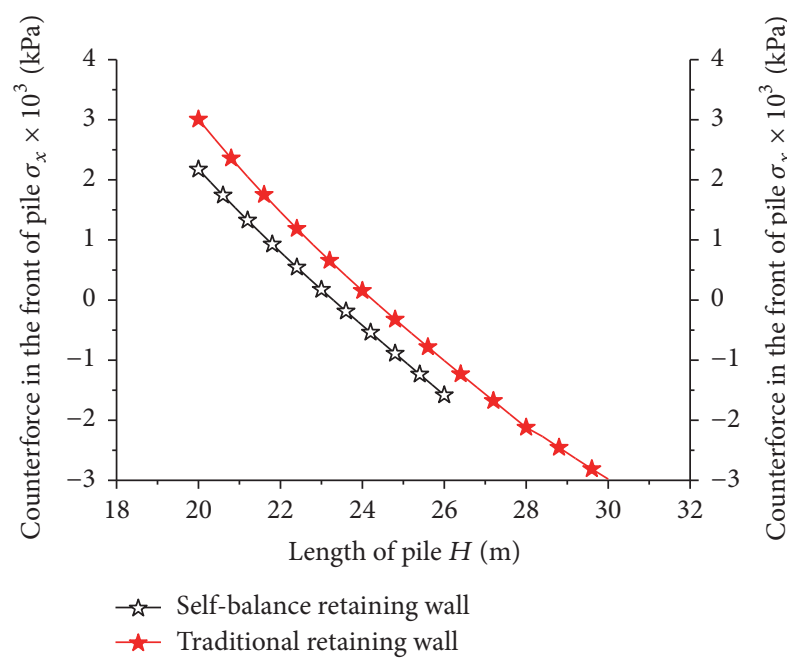

FIgURE 12: The soil pressure to the piles.

As shown in Figures 8 and 9, the internal force of selfbalance retaining wall is much less than that of cantilever pile retaining wall. Moreover, the counterforce of self-balance retaining wall is less than that of cantilever pile retaining wall. The main reason is as follows: (1) the self-balance retaining wall utilizes the vertical load of gravity retaining wall; (2) the dip angle of antisliding pile decreases the soil pressure. The peak of internal force of two kinds of support is compared in Table 2. As shown in Table 2, the piles bonding moment of self-balance retaining wall is only about $30 \%$ of

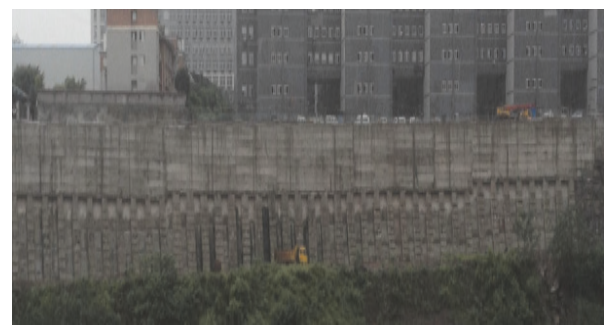

FIGURE 13: The self-balance retaining wall in light industrial zone D.

the traditional pile plate retaining wall. The shear force is only about $60 \%$ of the traditional pile plate retaining wall. And the counterforce of self-balance retaining wall is only about $70 \%$ of the traditional pile plate retaining wall. The comparison of pile reinforcement area is plotted in Figures 11 and 12.

As shown in Figures 11 and 12, the internal force of self-balance retaining wall is much less than that of traditional plate pile retaining wall. The steel area of self-balance retaining wall in the side of soil is about $50 \%$ of that in the traditional plate pile retaining wall. The steel area of selfbalance retaining wall in the side of face is about $30 \%$ of that in the traditional plate pile retaining wall because the crosssectional area of traditional retaining wall is much bigger than that of self-balance retaining wall. The self-balance retaining wall has a better economic effect.

4.5. Analysis of Prices. The statistics about main work quantities of two kinds of retaining wall is listed in Table 3.

As shown in Table 3, the cost of self-balancing retaining wall is less $55.4 \%$ than that of traditional pile retaining wall. If the construction measures fee of raking pile is considered, the practical engineering of self-balancing retaining wall can economize about 50\% compared to that of traditional pile retaining wall. So, it is obvious that the self-balancing retaining wall is more economical than the traditional pile retaining wall.

In fact, this project was completed in 2014, as shown in Figure 13. The cost of retaining wall per linear meter is 80,000 yuan. It saved about $13,000,000$ yuan compared with the design of traditional pile retaining wall.

\section{Conclusion and Prospection}

The self-balance retaining wall is put forward and used in 2003 as a new type of retaining wall. In the last ten years, there have been more than 10 engineering application examples 
TABLE 3: Single pile quantity statistics and cost estimate.

\begin{tabular}{|c|c|c|c|c|c|c|}
\hline Type of retaining wall & $\begin{array}{c}\text { Concrete } \\
/ \mathrm{m}^{3}\end{array}$ & $\begin{array}{c}\text { Reinforcing } \\
\text { steel bar/t }\end{array}$ & $\begin{array}{c}\text { Earth } \\
\text { cutting } / \mathrm{m}^{3}\end{array}$ & Rock cutting $/ \mathrm{m}^{3}$ & $\begin{array}{c}\text { Rubble } \\
\text { concrete } / \mathrm{m}^{3}\end{array}$ & $\begin{array}{l}\text { Total } \\
\text { /yuan }\end{array}$ \\
\hline Self-balance retaining wall & 84 & 11.23 & 16 & 24 & 102.92 & \\
\hline Traditional pile retaining wall & 340 & 28 & 40 & 100 & 0 & \\
\hline The proportion of saving & 0.75 & 0.59 & 0.6 & 0.76 & 0 & \\
\hline Unit price & 500 & 5000 & 200 & 300 & 450 & \\
\hline Self-balance retaining wall & 42000 & 56150 & 3200 & 7200 & 46314 & 154864 \\
\hline Traditional pile retaining wall & 170000 & 140000 & 8000 & 30000 & 0 & 348000 \\
\hline
\end{tabular}

with good effect. The deformation of self-balance retaining wall is much less than that of traditional retaining wall. The features of this technique are as follows:

(1) In the filling slope controlled by Coulomb's earth pressure, the self-balancing retaining wall has the following remarkable advantages.

(2) The self-balance retaining wall first utilizes this resource which expands the soil retaining effect from itself to the lower retaining wall with energy conservation and emissions reduction.

(3) The antislide raking pile can decrease the soil pressure.

(4) The dependence on the anchor tensile conditions is small or absent.

(5) The retaining wall has a rational stress mechanism and simple mechanical model and can be mastered by designers.

(6) The retaining wall has a low cost and good economic value.

(7) The retaining wall has small deformation and no strict requirement for filling materials.

While some researchers have objections about antiseismic property of the self-balance retaining wall because it is very top-heavy, the self-balance retaining wall has no recognized engineering calculation software. The antiseismic and calculation software will be studied in future by authors.

\section{Conflicts of Interest}

The authors declare that they have no conflicts of interest.

\section{Acknowledgments}

This work was supported by Projects nos. 0903005203452 and 106112017CDJXY200007 and supported by the Fundamental Research Funds for the Central Universities, Natural Science Foundation Project of CQ CSTC (no. cstc2017jcyjA1250).

\section{References}

[1] R. Huang, "Large-scale landslides and their sliding mechanisms in China since the 20th century," Chinese Journal of Rock Mechanics and Engineering, vol. 26, no. 3, pp. 433-454, 2007.
[2] Y. R. Zheng and Z. Y. Chen, Engineering Treatmennt of Slpoe and Landslide, China communications press, Beijing, China, 2006.

[3] Y. Lu, G. Deng, L. Yang, and D. Liu, "Study of mechanical behaviors of key blocks and characteristics of force transmit and stability coefficient of different stress states of landslides," Chinese Journal of Rock Mechanics and Engineering, vol. 33, no. 5, pp. 884-891, 2014.

[4] Y. F. Lu, L. P. Yang, and G. H. Hua, "A new joint constitutive model and a few new methods of stability coefficient calculation of landslides," Chinese Journal of Rock Mechanics and Engineering, no. 12, pp. 433-454, 2013.

[5] Y. F. Lu, M. Y. Tu, and D. F. Liu, "Joint constitutive model and new methods of stable factor calculation of landslides," Materials Research Innovations, vol. 18, pp. S2768-S2774, 2014.

[6] Y. Lu, "Deformation and failure mechanism of slope in three dimensions," Journal of Rock Mechanics and Geotechnical Engineering, vol. 7, no. 2, pp. 109-119, 2015.

[7] Z. H. Dai, "Study on distribution laws of landslide thrust and resistance of sliding mass acting on anti-slide piles," Chinese Journal of Rock Mechanics and Engineering, vol. 21, no. 4, pp. 517-521, 2002.

[8] A. J. Zhang, H. O. Mo, and W. Xiang, "Effect of lateral soil movement modes on behavior of stabilizing piles," Rock and Soil Mechanics, vol. 33, no. 9, pp. 2719-2724, 2012.

[9] R. Z. Wu and H. Q. Zhou, "Research on distribution law of landslide thrust of anchored anti-slide pile based on FLAC3D," Journal of Disaster Prevention, vol. 33, no. 5, pp. 548-555, 2013.

[10] J. Won, K. You, S. Jeong, and S. Kim, "Coupled effects in stability analysis of pile-slope systems," Computers and Geotechnics, vol. 32, no. 4, pp. 304-315, 2005.

[11] K. H. Cho, M. A. Gabr, S. Clark, and R. H. Borden, "Field P-y curves in weathered rock," Canadian Geotechnical Journal, vol. 44, no. 7, pp. 753-764, 2007.

[12] H. G. Poulos, Design of slope stabilizing piles, University of Sydney, Sydney, Australia, 1999.

[13] C.-Y. Chen and G. R. Martin, "Soil - Structure interaction for landslide stabilizing piles," Computers and Geotechnics, vol. 29, no. 5, pp. 363-386, 2002.

[14] S. Jeong, B. Kim, and J. Won, "Uncoupled analysis of stabilizing piles in weathered slopes," Computers and Geotechnics, vol. 30, no. 8, pp. 671-682, 2003.

[15] F. Cai and K. Ugai, "A subgrade reaction solution for piles to stabilise landslides," Geotechnique, vol. 61, no. 2, pp. 143-151, 2011.

[16] M. Son and S. Adedokun, "Effect of support characteristics on the earth pressure in a jointed rock mass," Canadian Geotechnical Journal, vol. 24, no. 1, pp. 1956-1967, 2015. 
[17] H.-B. Zhang, J.-J. Chen, X.-S. Zhao, J.-H. Wang, and H. Hu, "Displacement performance and simple prediction for deep excavations supported by contiguous bored pile walls in soft clay," Journal of Aerospace Engineering, vol. 28, no. 6, Article ID A4014008, 2015.

[18] C. W. W. Ng, J. Shi, D. Mašín, H. Sun, and G. H. Lei, "Influence of sand density and retaining wall stiffness on three-dimensional responses of tunnel to basement excavation," Canadian Geotechnical Journal, vol. 52, no. 11, pp. 1811-1829, 2015.

[19] M. Wyjadłowski, W. Puła, and J. Bauer, "Reliability of diaphragm wall in serviceability limit states," Archives of Civil and Mechanical Engineering, vol. 15, no. 4, pp. 1129-1137, 2015.

[20] S. S. Chowdhury, K. Deb, and A. Sengupta, "Behavior of underground strutted retaining structure under seismic condition," Earthquake and Structures, vol. 8, no. 5, pp. 1147-1170, 2015.

[21] S. Burlon, H. Mroueh, and I. Shahrour, "Influence of diaphragm wall installation on the numerical analysis of deep excavation," International Journal for Numerical and Analytical Methods in Geomechanics, vol. 37, no. 11, pp. 1670-1684, 2012.

[22] M. N. Houhou, F. Emeriault, R. Kastner, and S. Benmebarek, "Rétro-analyse tridimensionnelle d'une excavation profonde multisupportée instrumentée," European Journal of Environmental and Civil Engineering, vol. 14, no. 1-10, pp. 55-86, 2010.

[23] Y. Tan, Y. Lu, and F. Peng, "Semiempirical approach for estimation of DDC-induced deflections of sheet pile walls in peat," Journal of Performance of Constructed Facilities, vol. 24, no. 1, pp. 87-95, 2009.

[24] X. M. Ye, Inclined pile self balancing type retaining wall, 2012 (in Chinese).

[25] X. M. Ye and F. Gan, The vertical anchor pile retaining wall, July 2015 (in Chinese).

[26] X. M. Ye and F. Gan, The vertical anchor pile retaining wall, June 2015 (in Chinese).

[27] X. M. Ye and F. Gan, Folded plate pile retaining wall, 2015 (in Chinese).

[28] L. P. Guan, Research on mechanics model and the application of the balance retaining wall, Chongqing University, Chongqing, China, 2005.

[29] F. Luo and P. Li, Research on the balance of retaining wall inclined pile embedded in solid, Chongqing University, Chongqing, China, 2005. 

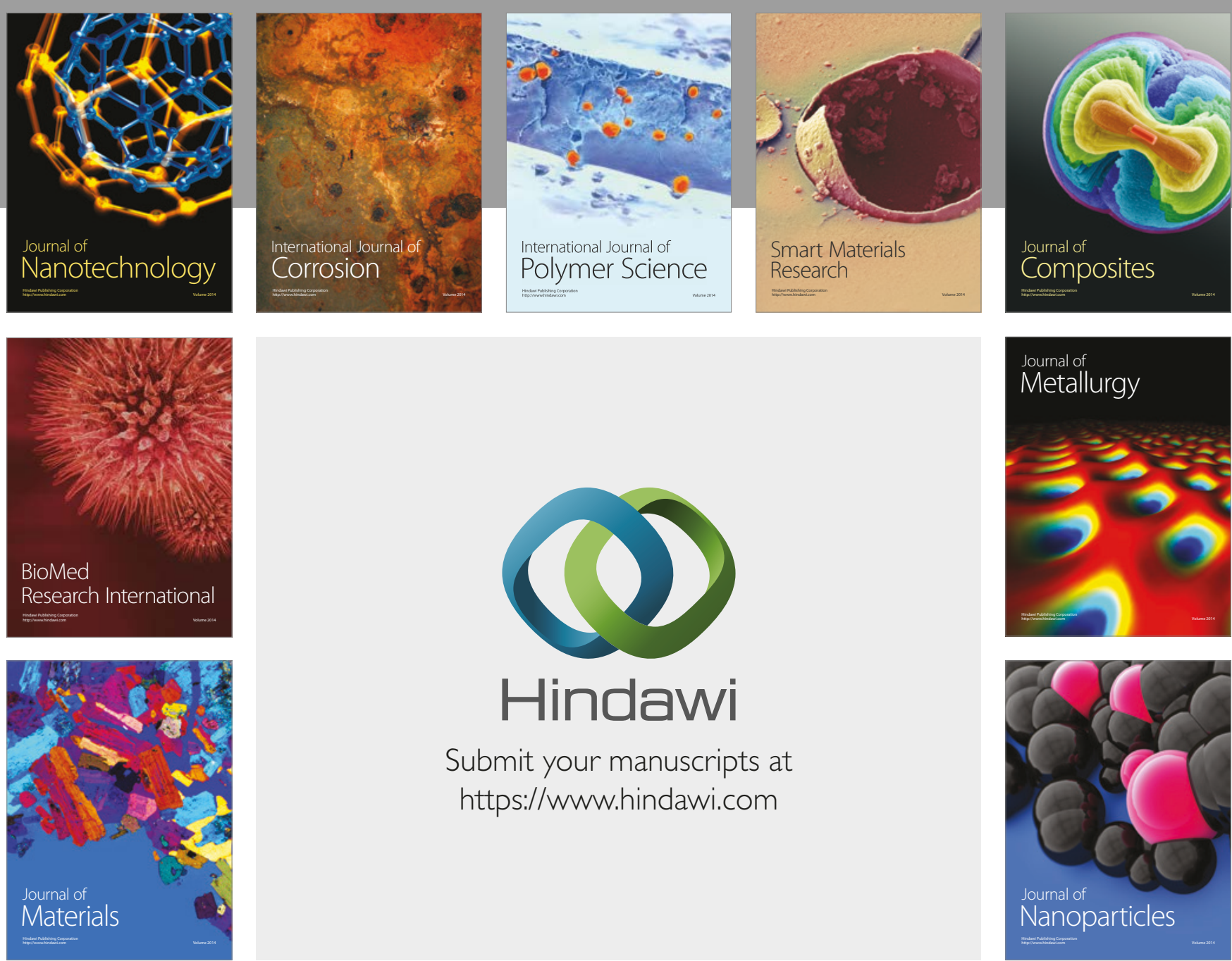

\section{Hindawi}

Submit your manuscripts at

https://www.hindawi.com
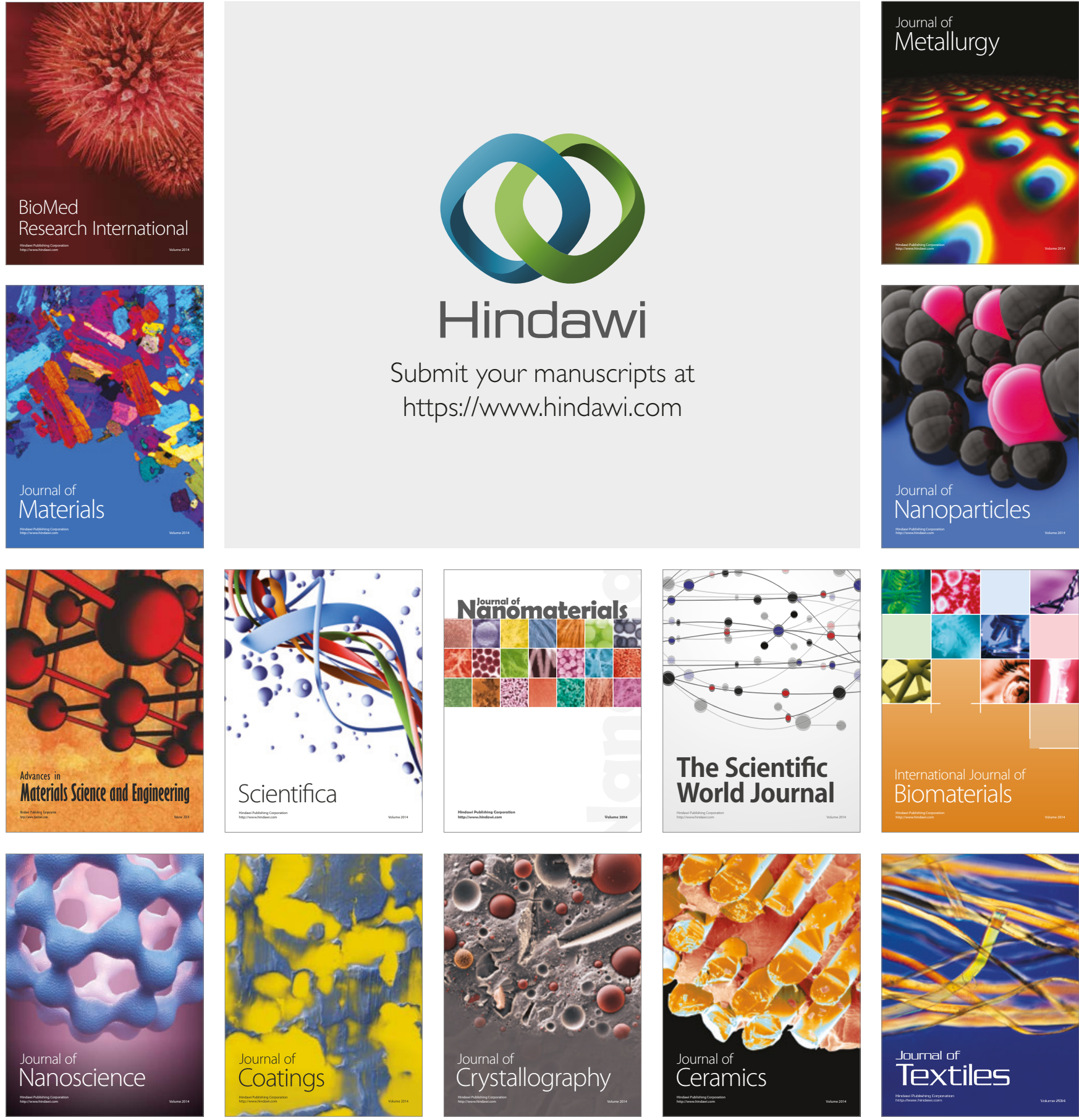

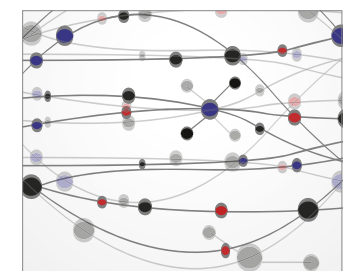

The Scientific World Journal
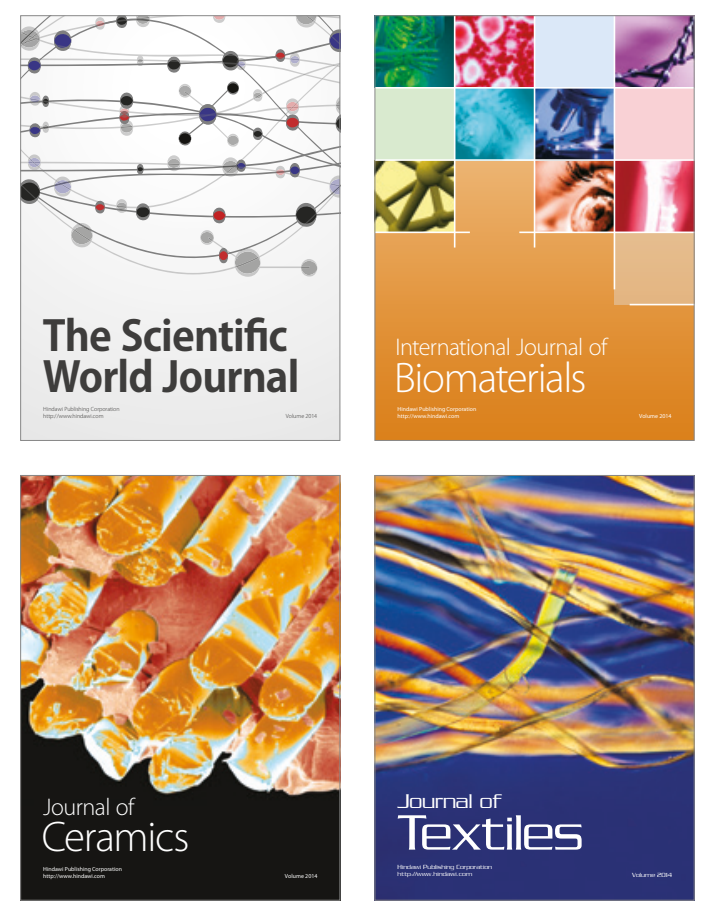